\title{
Laryngeal schwannoma: a case report with emphasis on sonographic findings*
}

\author{
Schwannoma laríngeo: relato de caso com ênfase nos achados ultrassonográficos
}

\section{Luis Ronan Marquez Ferreira de Souza ${ }^{1}$, Harley De Nicola ${ }^{2}$, Rosiane Yamasaki ${ }^{3}$, José Eduardo Pedroso ${ }^{4}$, Osíris de Oliveira Camponês do Brasil $^{4}$, Hélio Yamashita ${ }^{5}$}

Souza LRMF, De Nicola H, Yamasaki R, Pedroso JE, Brasil OOC, Yamashita H. Laryngeal schwannoma: a case report with emphasis on sonographic findings. Radiol Bras. 2014 Mai/Jun;47(3):191-193.

Abstract Schwannomas are benign nerve sheath tumors composed of Schwann cells, which normally produce the insulating myelin sheath covering peripheral, cranial and autonomic nerves. Twenty-five to forty-five percent of all schwannomas occur in the head and neck region, but location of such tumors in the larynx is rarely observed. The present report is aimed at describing a clinical case of laryngeal schwannoma, with emphasis on sonographic findings.

Keywords: Laryngeal neoplasms; Ultrasonography; Computed tomography.

Resu mo Schwannomas são tumores benignos derivados da bainha das células de Schwann de nervos motores, sensitivos e cranianos, sem conter elementos nervosos. Cerca de $25 \%$ a $45 \%$ dos casos ocorrem na região de cabeça e pescoço, mas a localização laríngea é rara. O objetivo do nosso estudo é descrever um caso clínico de schwannoma laríngeo, enfatizando-se os achados ultrassonográficos.

Unitermos: Neoplasias laríngeas; Ultrassonografia; Tomografia computadorizada.

\section{INTRODUCTION}

Schwannoma is a benign nerve sheath tumor composed of Schwann cells. Twenty-five to forty-five percent of all schwannomas occur in the head and neck region, and laryngeal involvement is rarely observed (in $0.1 \%$ to $1.5 \%$ of cases $)^{(1-3)}$. When present in this location, approximately $80 \%$ of these tumors affected the aryepiglottic fold, and $20 \%$ the vocal cords and vestibular folds ${ }^{(4)}$.

The main symptoms of such condition are secondary to the mass effect. Most common symptoms include dysphagia, dysphonia, pharyngeal globus sensation and, depending on the lesion size, respiratory distress with inspiratory stridor ${ }^{(1,4)}$.

Laryngeal schwannomas are usually diagnosed by means of direct laryngoscopy with a biopsy. However, this kind of

* Study developed at Escola Paulista de Medicina - Universidade Federal de São Paulo (EPM-Unifesp), São Paulo, SP, Brazil.

1. PhD, Associate Professor at Universidade Federal do Triângulo Mineiro (UFTM), Uberaba, MG, Brazil.

2. PhD, Collaborating Physician at Escola Paulista de Medicina - Universidade Federal de São Paulo (EPM-Unifesp), São Paulo, SP, Brazil.

3. PhD, Speech-language Pathologist, Department of Speech-Language Pathology and Audiology, Escola Paulista de Medicina - Universidade Federal de São Paulo (EPM-Unifesp), São Paulo, SP, Brazil.

4. MDs, Otorhinolaryngologists, ENT - Larynx and Voice Sector, Escola Paulista de Medicina - Universidade Federal de São Paulo (EPM-Unifesp), São Paulo, SP, Brazil.

5. PhD, Associate Professor, Escola Paulista de Medicina - Universidade Federal de São Paulo (EPM-Unifesp), São Paulo, SP, Brazil.

Mailing Address: Dr. Luis Ronan Marquez Ferreira de Souza. Departamento de Clínica Médica, Disciplina de Radiologia e Diagnóstico por Imagem, Universidade Federal do Triângulo Mineiro. Avenida Frei Paulino, 30, Abadia. Uberaba, MG, Brazil, 38025180. E-mail: luisronan@gmail.com.

Received February 13, 2013. Accepted after revision August 19, 2013. biopsy does not always provide a definite diagnosis because of the capsule that surrounds the tumor. With regard to diagnostic imaging methods, computed tomography $(\mathrm{CT})$ and magnetic resonance imaging (MRI) are most frequently indicated, although their findings are generally nonspecific and do not rule out other etiologies ${ }^{(5-7)}$.

The present report describes a case of laryngeal schwannoma with emphasis on sonographic findings.

\section{CASE REPORT}

A 25-year-old male patient with a history of slight vocal abnormality since childhood presented, in the last two years, a worsening in the quality of his voice, including a need to make increased effort to speak, dyspnea on mild effort and night snoring.

An otolaryngological examination showed respiratory stridor and usage of accessory muscles during phonation and respiration. Nasofibrolaryngoscopy showed an expansile cystlike lesion and noticeable superficial vascularization located on the right aryepiglottic fold with partial occlusion of the glottic opening (Figure 1).

Biopsy was then performed on the lesion, and the specimen was sent for anatomopathological analysis. Because of the respiratory impairment, the patient was tracheotomized before the surgery. The patient evolved with significant edema of the epiglottis and the biopsied region. The patient also presented marked odynophagia, which gradually improved.

The patient presented intense degree of vocal deviation characterized by roughness, breathiness, vocal tension and moments of diplophonia. To analyze the voice quality an acoustic spectrogram was performed. Acoustic spectrogram 
is a three-dimensional graph that provides important information about frequency range (vertical axis), time (horizontal axis), and amplitude (degree of browning of the tracing). In general, the better the voice quality, the greater the stability and less noise on the spectrum (Figure 2).

Contrast-enhanced CT demonstrated the presence of an ill-defined hypoattenuating expansile mass with heterogeneous enhancement, located in the right aryepiglottic fold, in the ipsilateral piriform recess. The lesion obstructed the laryngeal opening, with no signs of vascular or bone invasion (Figure 3).

Two days after the biopsy, ultrasonography was performed with the patient positioned in dorsal decubitus with cervical hyperextension. A large, predominantly hypoechoic solid mass $(3.8 \mathrm{~cm})$ was found in the aryepiglottic fold, inside the larynx, occluding almost the entire glottic opening. Such a nodule presented a slightly heterogeneous echotexture, with regular and well defined limits in its anterior portion and, ill-defined limits in its posterior portion (Figure 4). A Doppler study demonstrated moderate flow with spectral waves revealing a resistive index ranging from 0.57 to 0.63 in the center and on the border of the lesion. No atypical or enlarged cervical lymph nodes were identified. Ultrasonography could accurately determine that the solid mass did not invade adjacent structures such as the thyroid cartilage and the adjacent muscles.

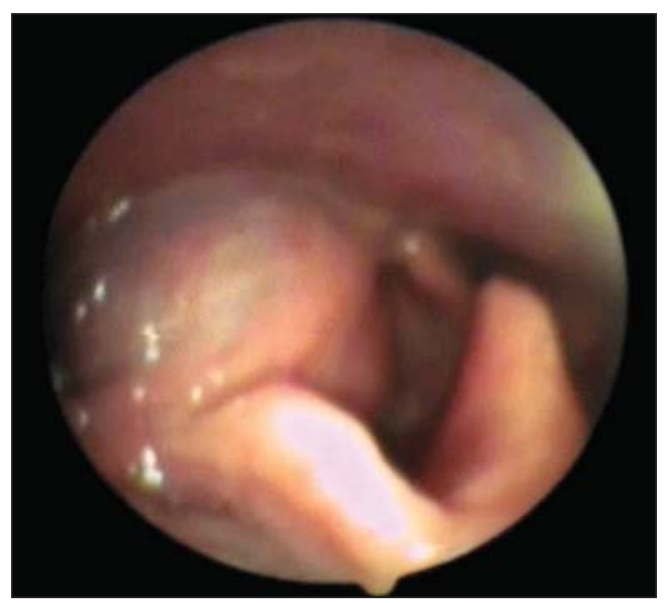

Figure 1. Nasofibrolaryngoscopy showed an expansive cystlike lesion and noticeable superficial vascularization located on the right aryepiglottic wall, with partial occlusion of the glottic opening.

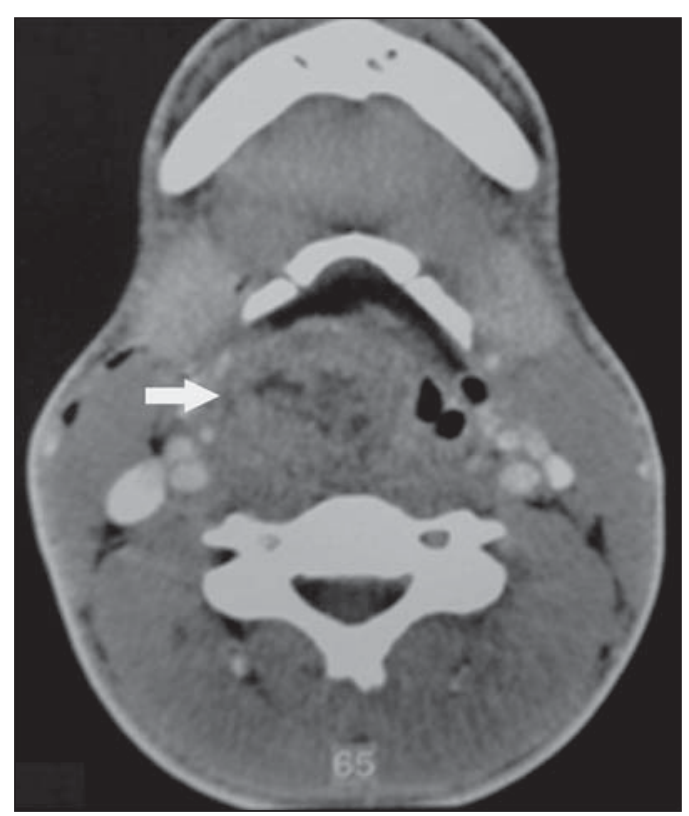

Figure 3. Axial, contrast-enhanced CT image. Note the ill-defined hypoattenuating expansile mass with heterogeneous enhancement located in the right aryepiglottic fold, in the ipsilateral piriform recess. The lesion obstructed the laryngeal opening, with no signs of vascular or bone invasion.

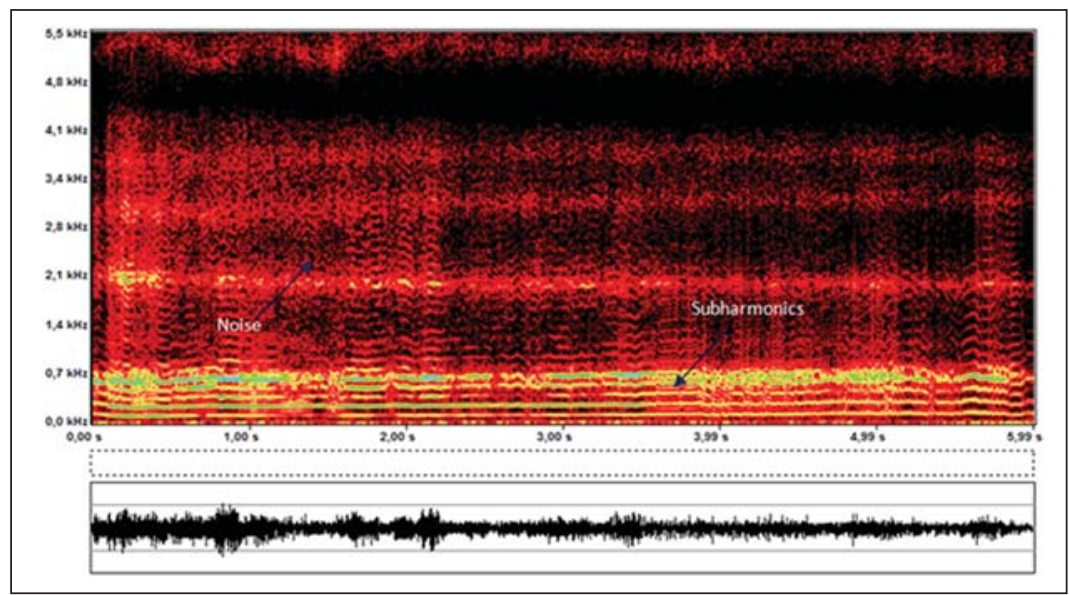

Figure 2. Spectrographic tracing of sustained vowel / (FonoView 1.0, CTS Informática). The first harmonics had an intense tracing (yellow color), indicating great effort required for voice production. Observe the tracing instability, presence of subharmonics, and noise on low and high frequencies.

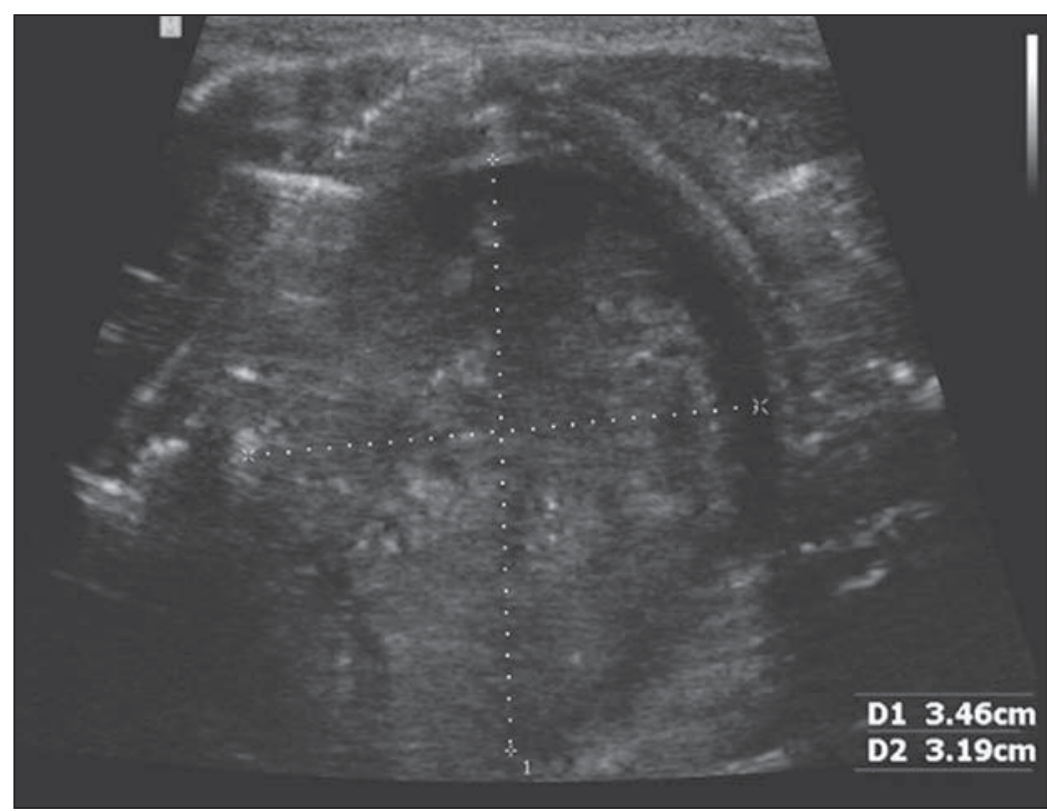

Figure 4. Sonographic image. A large, predominantly hypoechoic solid mass $(3.8 \mathrm{~cm})$ was found in the aryepiglottic fold, inside the larynx, occluding almost the entire glottic opening. This nodule presented a slightly heterogeneous echotexture, with regular and well defined limits in the anterior portion and, ill-defined limits in the posterior portion of the lesion. 


\section{DISCUSSION}

Laryngeal schwannomas are very rare benign, slow growing tumors, generally located in the submucosa of the supraglottic area. Main differential diagnoses include chondromas, adenomas, mucoceles, laryngoceles, lipomas and neurofibromas. Imaging findings of laryngeal schwannoma have been described in only few cases.

Malcolm et al. ${ }^{(8)}$ have described one case based on MRI that revealed a slightly heterogeneous mass that was isointense in relation to muscle on T1-weighted, and hyperintense on T2-weighted sequences, with heterogeneous enhancement. Plantet et al. ${ }^{(6)}$ have described two cases where non-contrastenhanced CT demonstrated hyperdensity in the lesion center and peripheral hypodensity. In one of such cases, MRI demonstrated slight hyperintensity in the lesion center, peripheral hypointensity on $\mathrm{T} 1$-weighted images, and peripheral hyperintensity on T2-weighted images. Such findings were nonspecific and, for this reason, it was not possible to make a differential diagnosis with other entities, except for lipomas, which were isointense in relation to subcutaneous fat on all the MRI sequences.

Ultrasonography is the first choice in the investigation of cervical pathological conditions. However, in the specific case of the larynx, there are divergent views in the medical literature, and the role of ultrasonography is still to be well established. With technological advances and higher-frequency transducers allowing for a better imaging resolution, some authors have recently supported the use of ultrasonography for studying the larynx, particularly in the investigation of tumor-like lesions ${ }^{(9-12)}$. As far as the authors are concerned, descriptions of sonographic findings of laryngeal schwannomas are not found in the medical literature.

Kuribayashi et al. ${ }^{(10)}$ have investigated whether stages T1 and T2 of glottic carcinoma could be demonstrated by means of percutaneous ultrasonography. As the method was limited to detectable tumors, sonographic and laryngoscopic findings related to supraglottic and infraglottic impairment were consistent in all cases. None of the cases presented any false positive or false negative results.

Xia et al. ${ }^{(11)}$ have analyzed the value of ultrasonography in the diagnosis of hypopharyngeal carcinoma, considering the following parameters: location, invasion of adjacent tissues and sonographic morphology. Such authors have observed hypoechogenic masses in all the tumors and irregular masses in $30 \%$ of their cases. Color Doppler demonstrated the presence of hypervascular tumors in $69.7 \%$ of cases. According to their study, $85.3 \%$ of the lesions were better evaluated by ultrasonography than by CT.

In the present case, ultrasonography revealed a predominantly hypoechoic and subtle heterogeneous solid mass with a regular contour. Color Doppler demonstrated minimal flow and a medium to high resistance index. In cases of laryngeal tumors, invasion of the thyroid cartilage is an independent determining factor for worse prognosis ${ }^{(11)}$. In the present case, it was possible to clearly identify that there was no invasion of the thyroid cartilage, which is expected in cases of benign tumors, although the posterior limits of the lesion were not clearly identified at echography, perhaps because of the dimensions of the lesion. Other technical factors may have contributed towards the difficulty in visualizing the posterior limits of the lesion. Loveday ${ }^{(9)}$ has classified the posteriorly located deep structures as "blind spots" on sonographic images of the larynx, and attributed them to the air column within the larynx.

\section{CONCLUSION}

Laryngeal ultrasonography is rarely utilized as a diagnostic method. In the present case, this method provided relevant additional information on the lesion texture, vascular pattern and absence of invasion of the thyroid cartilage, although the posterior limits of the lesion could not be appropriately visualized by means of this method.

\section{REFERENCES}

1. Melo ECM, Tiago RSL, Brasil OOC, et al. Schwannoma de laringe: relato de caso. Rev Bras Otorrinolaringol. 2004;70:268-71.

2. Barnes L, Ferlito A. Soft tissue neoplasms. In: Ferlito A, editor. Neoplasms of the larynx. Edinburgh: Churchill Livingstone; 1993. p. 277-9.

3. Jones SR, Myers EN, Barnes L. Benign neoplasms of the larynx. Otolaryngol Clin North Am. 1984;17:151-78.

4. Ebmeyer J, Reineke U, Gehl HB, et al. Schwannoma of the larynx. Head \& Neck Oncology. 2009;1:24.

5. Rognone E, Rossi A, Conte M. et al. Laryngeal schwannoma in an 8-year-old boy with inspiratory dyspnea. Head Neck. 2007;29:9725 .

6. Plantet MM, Hagay C, De Maulmont C, et al. Laryngeal schwannomas. Eur J Radiol. 1995;21:61-6.

7. Tzagkaroulakis A, Stivaktakis J, Nikolopoulos T, et al. Ancient schwannoma of the true vocal cord. ORL J Otorhinolaryngol Relat Spec. 2003;65:310-3.

8. Malcolm PN, Saks AM, Howlett DC, et al. Case report: magnetic resonance imaging (MRI) appearances of benign schwannoma of the larynx. Clin Radiol. 1997;52:75-6.

9. Loveday EJ. Ultrasound of the larynx. Imaging. 2003;15:109-14.

10. Kuribayashi S, Miyashita T, Nakamizo M, et al. Utility of sonography for evaluation of clinical T1 and T2 glottic carcinoma. J Ultrasound Med. 2009;28: 1429-40

11. Xia CX, Zhu Q, Cheng Y, et al. Sonographic assessment of hypopharyngeal carcinoma: preliminary study. J Ultrasound Med. 2011 ; 30:217-25.

12. Singh M, Chin KJ, Chan VW, et al. Use of sonography for airway assessment: an observational study. J Ultrasound Med. 2010;29:7985. 